\title{
Motivated visual search with target-nontarget confusability*
}

\author{
STEVEN M. PINE and JOHN E. HOLMGREN \\ University of Maryland, College Park, Maryland 20742
}

\begin{abstract}
A visual search task with target-nontarget confusability was studied in conjunction with a reward condition. Data were obtained from six Ss in a single-target-item visual search task. Displays were linear arrays of letters tachistoscopically presented. In terms of the latency and accuracy of responses, search was more difficult in displays with confusable targets and nontargets, whereas reward tended to produce faster and more accurate search. It was concluded that both the reward and confusability conditions served to alter the S's search strategy.
\end{abstract}

Visual search tasks, in which Ss are asked to search through a visually presented linear display of symbols for one or more previously displayed target symbols and respond "yes" or "no" depending on whether or not the target(s) appeared in the display, have been used to in vestigate characteristics of 'Ss' search strategy (Sternberg, 1967, 1968; Nickerson, 1969; etc.). An exhaustive strategy is implied when the slopes of the functions which relate the mean reaction time to the display size for the "yes" and "no" responses are roughly equal, whereas unequal slopes are often interpreted as indicating a self-terminating search in which an $\mathrm{S}$ stops processing as soon as the target is found. For example, in the case where a single target is to be searched for, it is well established (Atkinson, Holmgren, \& Juola, 1969; Briggs \& Blaha, 1969) that "yes" and "no" latency functions have the same slope. However, when more than one target is searched for, or when there are redundant items in the display, the slopes are generally not parallel (Sternberg, 1967; Estes \& Bjork, 1971; Estes, 1972).

Apparently, manipulating the number of targets and the number of redundant items may produce strategy changes with respect to the simple yes-no search task. The question then arises, what other manipulations, if any, might produce strategy changes? It seems reasonable that the introduction of motivation, in the form of appropriate reward conditions, might produce such a result. For example, under the incentive of reward, Ss might choose a self-terminating search strategy instead of the generally employed exhaustive strategy. Unfortunately, there is little existing research which could be used to substantiate such a line of reasoning. Several studies have used reward to motivate performance (Estes \& Bjork, 1971; Estes, 1972; Briggs \& Blaha, 1969); very few studies, however, have included reward as an independent variable.

Another way in which deviations from the normal result for single target search might occur is through the

\footnotetext{
*This paper is based upon a thesis submitted to the University of Maryland by the senior author in partial fulfillment of the requirements for the MS degree.
}

introduction of target-nontarget visual confusability. Results from several studies have shown that target-nontarget confusability tends to make processing more difficult, as measured by decreases in response accuracy and by increases in mean latency (Estes, 1972; Chase \& Posner, 1965; McIntyre, Fox, \& Neale, 1971). In addition, the Chase and Posner study compared the effects of visual and acoustic confusability on several search tasks. Their results indicated that, for a visual comparison task, visual confusability increased the slope of the line which related mean latency to display size. However, the visual comparison task differs from the visual search task in that both the target and the display are visually present at the same time, instead of the target being held in memory while the display is shown, as is the case in the visual search paradigm. In fact, the visual search task was one of the other tasks used in the Chase and Posner study. In this case, the slope effects due to visual confusability, although in the same direction as for the visual comparison task, were not nearly as large. Therefore, further explication of the effects of visual confusability on visual search processes seems to be called for in addition to the exploration of motivation factors.

\section{METHOD}

\section{Stimuli and Apparatus}

Stimulus materials for this study were $3202 \times 2$ in. slides, of which 160 were display slides and 160 were target slides. The display slides consisted of a horizontal row of from one to four consonants flanked by the number " 2 ," which served only as a delimiter. A single consonant, chosen from one of two sets of consonants (as explained in the Procedure and Design section), appeared on each target slide. Each of the display slides was paired with one of the target slides.

Slides were viewed binocularly by means of a Scientific Prototype Model GB programmable three-field tachistoscope. The longest display on any one slide subtended a visual angle of about $1.5 \mathrm{deg}$. The RT, defined as the interval (measured in milliseconds) between the onset of the display slide and the depression of either a "yes" or a "no" response button, was recorded on a Hewlett-Packard digital timer. A standard doorbell was used to indicate correct subdeadline responses, emitted when a reward condition was in effect. 
Table 1

Target and Display Examples of Experimental Conditions for Display Size of Three With S1 the Reward Set

\begin{tabular}{|c|c|c|c|c|}
\hline & Conditions & & Targets & Displays \\
\hline \multirow{2}{*}{ Reward } & Nonconfusable & $\begin{array}{l}\text { Yes } \\
\text { No }\end{array}$ & $\begin{array}{l}B \\
G\end{array}$ & $\begin{array}{l}\text { 2LBT2 } \\
\text { 2KHL2 }\end{array}$ \\
\hline & Confusable & $\begin{array}{l}\text { Yes } \\
\text { No }\end{array}$ & $\begin{array}{l}\text { B } \\
\text { G }\end{array}$ & $\begin{array}{l}\text { 2CBG2 } \\
\text { 2QCS2 }\end{array}$ \\
\hline \multirow{2}{*}{ Nonreward } & Nonconfusable & $\begin{array}{l}\text { Yes } \\
\text { No }\end{array}$ & $\begin{array}{l}\mathrm{T} \\
\mathrm{H}\end{array}$ & $\begin{array}{l}\text { 2SBT2 } \\
\text { 2CBQ2 }\end{array}$ \\
\hline & Confusable & $\begin{array}{l}\text { Yes } \\
\text { No }\end{array}$ & $\begin{array}{l}\mathrm{T} \\
\mathrm{H}\end{array}$ & $\begin{array}{l}\text { 2TLF2 } \\
\text { 2FKT2 }\end{array}$ \\
\hline
\end{tabular}

\section{Procedure and Design}

Six Ss were run in 10 experimental sessions, each consisting of two 80 trial runs through the 160 pairs of slides with a 5-min break between runs. Slides were randomized between sessions, but all Ss were shown the same random sequences. Each trial consisted of the following sequence of events: (1) A target letter was shown for $2 \mathrm{sec}$. (2) A $1 / 2-\mathrm{sec}$ delay occurred, during which the $S$ saw a fixation point. (3) The display slide was shown for $3 \mathrm{sec}$. (4) The $S$ was to search the display for the target and to respond either "yes" or "no" by pressing an appropriate button, depending on whether or not the target appeared in the display. (5) When the reward condition was in effect (target letter a member of a predefined set of consonants), a response emitted faster than a fixed deadline caused a bell to ring, indicating that a bonus was earned if the response was correct. Fast incorrect responses were penalized by deducting a sum of money equal to the bonus. (6) When the reward condition was not in effect (target letter not from the reward set of letters), a bonus could not be earned and feedback was not given.

The consonants used on each slide were selected from two mutually exclusive sets of consonants, designated $\mathrm{S} 1$, and $\mathrm{S} 2$. Set $S 1$ consisted of the letters $B, C, G, Q, S$, and $S 2$ contained $L$, $\mathrm{F}, \mathrm{H}, \mathrm{K}, \mathrm{T}$. There were three factors of major interest in the study: reward vs nonreward, confusable vs nonconfusable, and yes vs no. These three factors combined factorially to produce eight equally likely experimental conditions, i.e., display types. Table 1 provides an example of each for a display size of three. There were four display sizes for each of the eight display types and five letters in each set (each set applying to four display types) giving 4 by 8 by $5=160$ display slides. Each factor is further explained below.

Reward-Nonreward Factor. One of the sets, S1 or S2, was assigned to each $\mathrm{S}$, counterbalancing across Ss, and was defined as the reward set for that $S$. If the target letter belonged to the reward set (randomly selected), Ss were eligible to earn a monetary reward (one penny) for correct responses emitted faster than a fixed deadline of about $700 \mathrm{msec}$ (determined from pilot data to be the point at which reward could be earned $80 \%$ of the time).

Confusable-Nonconfusable Factor. In the visually confusable condition, targets and nontargets were selected from the same set. Therefore, in the confusable case, both the target and nontarget were either rounded letters (for Set S1) or squared letters (for Set S2). This was very similar to the visual confusability condition used in the Chase and Posner (1965) study.

Yes-No Factor. In half the trials the target letter appeared in one of the serial positions of the display; this was the "yes" condition. For the other half of the trials, the target did not appear in the display; this was the "no" condition.

\section{Subjects}

Four female and two male University of Maryland undergraduates, none of whom had prior laboratory experience with search tasks, served as Ss. An hourly wage was paid to each $\mathrm{S}$ over 10 experimental sessions. In addition, a bonus of one penny per correct subdeadline response was paid in the reward condition. This bonus could accumulate to $\$ 8$ over the 10 sessions.

\section{RESULTS}

The latency and error data used in the analysis were averaged across all six Ss. The data for each $\mathrm{S}$ was averaged over 10 experimental sessions. Excluded from the analysis were the data collected during the initial session and the 15 practice trials which preceded each session. In addition, only latencies associated with correct responses were used in computing mean reaction times.

\section{Latency Data}

A linear fit in a least squares sense was made to the four points for each of the eight curves shown in Figs. 1a and $1 \mathrm{~b}$. The slopes and intercepts of these fits were analyzed in separate analyses of variance. The interaction between target item type (Set S1 or Set S2) and nontarget item type was significant for both the slopes and the intercepts, $F(1,5)=85.54, p<.001$, and $F(1,5)=12.76, p<.025$, respectively. The only other

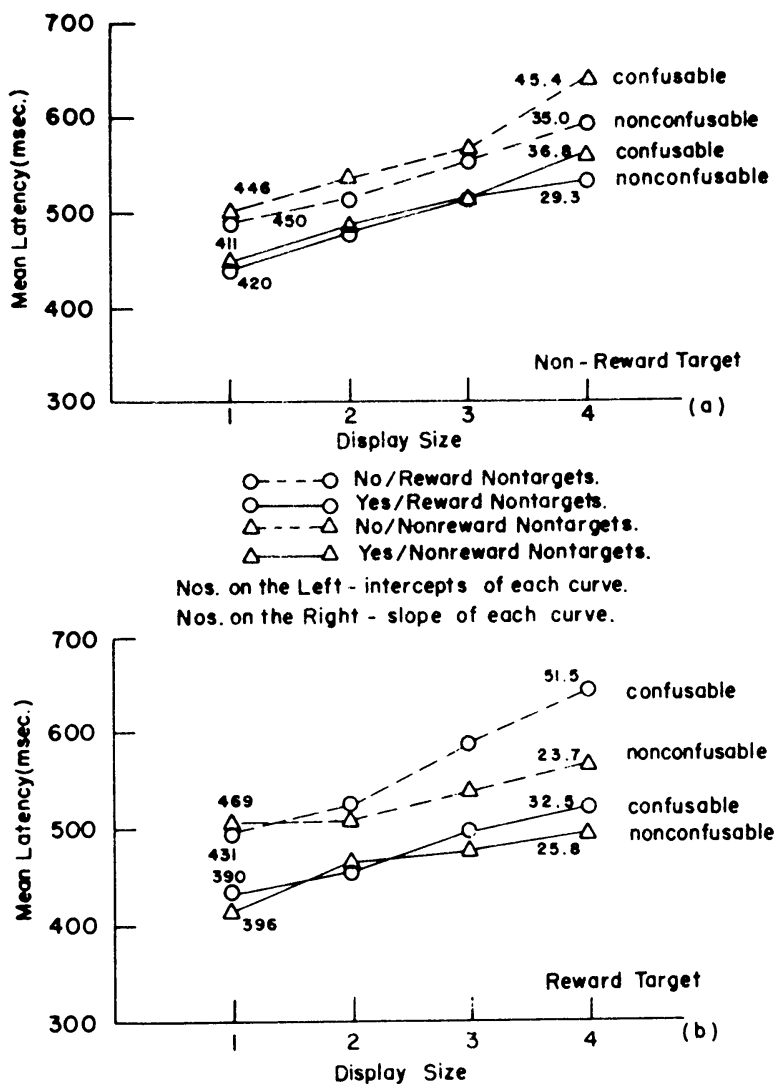

Fig. 1. Mean latency of positive and negative responses for confusable and nonconfusable conditions vs display size when target is from (a) nonreward set, (b) reward set, averaged over six Ss. 
Table 2

The Percentage of Errors and the Percentage of Reward for Six Subjects at All Conditions

\begin{tabular}{|c|c|c|c|c|c|c|c|c|c|c|}
\hline & \multirow[b]{3}{*}{ Percentage } & \multicolumn{8}{|c|}{ Conditions } & \multirow{3}{*}{$\begin{array}{c}\text { Average } \\
\text { Over } \\
\text { Conditions }\end{array}$} \\
\hline & & \multicolumn{2}{|c|}{$\begin{array}{l}\text { Rewarc } \\
\text { Confusable }\end{array}$} & \multicolumn{2}{|c|}{$\begin{array}{l}\text { Targets } \\
\text { Nonconfusable }\end{array}$} & \multicolumn{2}{|c|}{$\begin{array}{l}\text { Nonrewar } \\
\text { Nonconfusable }\end{array}$} & \multicolumn{2}{|c|}{$\begin{array}{l}\text { Targets } \\
\text { Confusable }\end{array}$} & \\
\hline & & Yes & No & Yes & No & Yes & No & Yes & No & \\
\hline \multirow{2}{*}{$6 \mathrm{Ss}$} & Errors & .035 & .023 & .017 & .019 & .033 & .015 & .061 & .023 & .028 \\
\hline & Reward & .870 & .790 & .890 & .860 & -- & -- & -- & -- & .853 \\
\hline
\end{tabular}

significant effect was the yes ve no factor for intercepts, $\mathrm{F}(1,5)=24.05, \mathrm{p}<.005$.

Matched $t$ tests were used to carry out paired comparisons. For the nonreward conditions shown in Fig. 1 a and comparing yes slopes to no slopes, within the confusable conditions and separately within the nonconfusable conditions, no significant slope differences were found. For the reward target case of Fig. 1b, however, the slopes between the yes and no responses for the confusable condition were significantly different, $F(5)=2.91, p<.025$. The intercepts for these same pairs of curves did not vary significantly.

\section{Error and Reward Data}

Table 2 gives the percentage of errors (\% err) and the percentage of reward (\% rwd) for each S and for the six Ss taken together. On the average, the Ss were rewarded on $85 \%$ of the opportunities for reward and made an average of $2.8 \%$ errors over all trials. There were more errors made for the reward conditions than for the nonreward conditions, and more errors for the confusable than for the nonconfusable condition. The Wilcoxon matched pairs test was carried out on the six Ss' data to test individual comparisons between conditions on the error data. It was found that for the reward condition there were no significant differences in error percentages comparing the "yes" to the "no" responses for either the confusable or the nonconfusable cases. Under the nonreward conditions, however, there were more errors made for the "yes" than for the "no" responses for both confusable and nonconfusable cases with the greater difference occurring for the confusable case $(p<.025)$.

\section{DISCUSSION}

\section{Effects of Confusability}

The strongest effects of this study were the interactions between target type (whether from Set S1 or S2) and nontarget type, and this was a direct demonstration of target-nontarget confusability. It would appear that target-nontarget confusability made it more difficult for the Ss to search the displays for target letters. This follows from the findings that the intercepts were higher and the slopes larger for the confusable compared to the nonconfusable conditions. In addition, there were more errors made on the confusable conditions.

\section{Effects of Reward}

If one was to assume that there was no influence in this experiment due to reward, there shiould be no significant differences between the confusable and the nonconfusable curves of the nonreward condition as compared to the confusable and nonconfusable curves for the reward condition. This would be true since the reward and the nonreward target conditions would only imply a categorical difference between the Sets $\mathrm{S} 1$ and S2, and there were no significant response differences between these sets. Therefore, it is logical to assume that any significant differences which were observed between the conditions of Figs. 1a and $1 \mathrm{~b}$ were directly attributable to the effects of reward.

For the nonreward curves shown in Fig. 1a, no significant differences were found between the "yes" and the "no" responses in terms of processing rate; but in terms of errors the "yes" responses were less accurate than their corresponding "no" responses. Since the Ss could not be rewarded for this group of conditions, it reduces to a simple confusability experiment with single target search. The slope changes found for mean reaction time curves for confusability are consistent with what has been found in previous studies (Estes, 1972; Chase \& Posner, 1965). Furthermore, the parallel nature of the "yes" and "no" response curves for mean RT is an established result for single target search (Holmgren, Juola, \& Atkinson, 1969; Briggs \& Blaha, 1969).

When the reward condition was operative, however, the results deviated in several important ways from what was obtained for the nonreward condition. Overall there were $50 \%$ fewer errors for the reward condition; and the "yes"-"no" error differences, in evidence for both the confusable and the nonconfusable conditions for nonreward, were no longer in evidence for reward.

Another deviation in the results for the reward conditions as compared to nonreward was that the "yes" and "no" responses were not always parallel. Instead, the confusable condition, i.e., both target and nontarget from the reward set, produces a significantly larger slope for the "no" responses. Such slope effects have customarily been interpreted as indicating self-terminating search (Atkinson, Holmgren, \& Juola, 1969; Nickerson, 1966; Sternberg, 1968). The interpretation is that the $\mathrm{S}$ terminates searching through the display as soon as a target is found, instead of searching every item of the display. Consequently, the slopes for the "no" curves are larger than the slopes for the "yes" curves. Estes and Bjork (1972) have stated that self-terminating search may require that the Ss be properly motivated. It is conceivable, therefore, that Ss are able to alter their search strategies in accordance to the demands of the task. In this instance, exhaustive search may have been replaced by self-terminating search when a deadline had to be beat and the task was compounded by confusability.

\section{Conclusion}

The evidence from this study on the role of confusability on multiple element display processing is supportive of the previous research in this area (Chase \& Posner, 1965; Estes, 1971, 1972; McIntyre, Fox, \& Neale, 1970). The previous studies which used error and/or latency data have also reported decreases in processing speed and increases in the probability of error due to confusability. The results from this study, however, indicate that target-non target confusability can affect the slopes of the mean latency curves as well as the intercepts. 
The influence of reward was found to go beyond the simple intercept effects which would have been expected based on the few previous studies on reward (La Berge \& Tweedy, 1964; Doll, 1969). Slope changes in the mean RT curves as a function of reward condition indicated that reward had a significant effect on the rate of item comparison as well as on the accuracy of the responses. In particular, these slope changes resulted in slope differences between the "yes" and "no" mean latency curves for the confusable condition with the rewarded target. This implies that the manipulated variables may have altered the Ss' search strategy, producing a self-terminating strategy instead of the exhaustive strategy which is usually found for single target visual search tasks.

\section{REFERENCES}

Atkinson, R. C., Holmgren, J. E., \& Juola, J. F. Processing time as influenced by the number of elements in a visual display. Perception \& Psychophysics, 1969, 6, 321-326.

Briggs, G. E., \& Blaha, J. Memory retrieval and central comparison time in information processing. Journal of Experimental Psychology, 1969, 79, 395-402.

Chase, W. G., \& Posner, M. I. The effects of auditory and visual confusability on visual and memory search tasks. Paper presented at the meeting of the Midwestern Psychological Association, Chicago, May 1965.

Doll, T. J. Motivation, reaction time, and the contents of active verbal memory. Journal of Experimental Psychology, 1971, 87, 29-36.

Estes, W. K. Interactions of signal and background variables in visual processing. Perception \& Psychophysics, 1972, 12 , 278-286.
Estes, W. K., \& Bjork, E. L. Detection and placement of redundant signal elements in tachistoscopic displays of letters. Perception \& Psychophysics, 1971, 9, 439-442.

La Berge, D., \& Tweedy, J. R. Selective attention: Incentive variables and choice reaction time. Psychonomic Science, 1967, 8, 341-342.

McIntyre, C., Fox, R., \& Neale, J. Effects of noise similarity and redundancy on the information processed from brief visual displays. Perception \& Psychophysics, 1970, 7, 328-332.

Nickerson, R. S. Response times with a memory-dependent decision task. Journal of Experimental Psychology, 1966, 72, 761-769.

Sternberg, S. Scanning a persisting visual image versus a memorized list. Paper presented at the Annual Meeting of the Eastern Psychological Association, 1967.

Sternberg, S. The discovery of processing stages: Extensions of Donders method. Paper presented at the Donders Centenary Symposium on Reaction-Time held at the Instituut Voor Perceptie Onderzoek, Eindhaven, The Netherlands, August 1968.

\section{NOTE}

1. Due to an equipment breakdown, S2 was run for two fewer sessions than the other Ss, i.e., 8 sessions instead of 10 . Ss' data was found to be congruous to the results of the other Ss' data and was, therefore, included in the data analy sis.

(Received for publication February 20, 1974.) 